\title{
The herbal extract KCHO-1 exerts a neuroprotective effect by ameliorating oxidative stress via heme oxygenase-1 upregulation
}

\author{
DONG-SUNG LEE ${ }^{1 *}$, WONMIN KO ${ }^{2 *}$, BONG-KEUN SONG $^{3 *}$, ILHONG SON $^{4}$, \\ DONG-WOUNG KIM ${ }^{5}$, DAE-GIL KANG ${ }^{6}$, HO-SUB LEE ${ }^{6}$, HYUNCHEOL OH ${ }^{2}$, \\ JUN-HYEOG JANG ${ }^{7}$, YOUN-CHUL KIM ${ }^{2}$ and SUNGCHUL KIM ${ }^{8}$
}

${ }^{1}$ Department of Pharmacy, Chosun University, Dong-gu, Gwangju 61452; ${ }^{2}$ Department of Pharmacy, Wonkwang University;

${ }^{3}$ Department of Internal Medicine, School of Oriental Medicine; ${ }^{4}$ Department of Neurology, Inam Neuroscience Research

Center, Sanbon Medical Center, College of Medicine, Wonkwang University, Iksan, Jeollabuk-do 54538;

${ }^{5}$ Center of Integrative Medicine, Department of Internal Medicine, Wonkwang University Gwangju Hospital, Gwangju 61729;

${ }^{6}$ Hanbang Body-Fluid Research Center, Wonkwang University, Iksan, Jeollabuk-do 54538;

${ }^{7}$ Department of Biochemistry, Inha University School of Medicine, Incheon 22212; ${ }^{8}$ ALS/MND Center

of Wonkwang University Korean Medical Hospital, Gwangju 61729, Republic of Korea

Received April 22, 2015; Accepted March 18, 2016

DOI: $10.3892 / \mathrm{mmr} .2016 .5129$

\begin{abstract}
KCHO-1 is a novel product comprised of $30 \%$ ethanol extracts obtained from nine medical herbs, which are commonly used in traditional Korean and Chinese medicine. The nine herbs include Curcuma longa, Salvia miltiorrhiza, Gastrodia elata, Chaenomeles sinensis, Polygala tenuifolia, Paeonia japonica, Glycyrrhiza uralensis, Atractylodes japonica and processed Aconitum carmichaeli. Recent studies have reported the beneficial effects of these herbs. The present study aimed to investigate the direct neuroprotective effects of KCHO-1 on HT22 mouse hippocampal cells, and to determine the possible underlying mechanisms. KCHO-1 significantly suppressed glutamateand hydrogen peroxide $\left(\mathrm{H}_{2} \mathrm{O}_{2}\right)$-induced cell damage, and reactive oxygen species generation. In addition, $\mathrm{KCHO}-1$ increased the mRNA and protein expression levels of heme oxygenase (HO)-1. Tin protoporphyrin, which is an inhibitor of $\mathrm{HO}$ activity, partially suppressed the effects of KCHO-1. Furthermore, KCHO-1 significantly upregulated nuclear
\end{abstract}

Correspondence to: Professor Youn-Chul Kim, Department of Pharmacy, Wonkwang University, 460 Iksan-daero, Iksan, Jeollabuk-do 54538, Republic of Korea

E-mail: yckim@wku.ac.kr

Professor Sungchul Kim, ALS/MND Center of Wonkwang University Korean Medical Hospital, 543-8 Juwol Dong, Nam-gu, Gwangju 61729, Republic of Korea

E-mail: kscndl@hanmail.net

*Contributed equally

Key words: KCHO-1, neuroprotective effects, mouse hippocampal HT22 cells, oxidative stress, heme oxygenase-1 factor erythroid-derived 2-related factor-2 (Nrf2) nuclear translocation. Extracellular signal-regulated kinase (ERK) activation also appeared to be associated with $\mathrm{KCHO}$-1-induced HO-1 expression, since the ERK inhibitor PD98059 suppressed HO-1 expression and prevented KCHO-1-induced cytoprotection. The results of the present study suggested that KCHO-1 may effectively prevent glutamate- or $\mathrm{H}_{2} \mathrm{O}_{2}$-induced oxidative damage via Nrf2/ERK mitogen-activated protein kinase-dependent HO-1 expression. These data suggest that KCHO-1 may be useful for the treatment of neurodegenerative diseases.

\section{Introduction}

Reactive oxygen species (ROS) are biologically significant due to their role in cellular redox signaling (1). It has been reported that ROS may induce cellular damage and increase physiological dysfunction (2). In locations where ROS accumulate, oxidative damage occurs, which has been linked to a diverse range of neurodegenerative disorders, including Alzheimer's disease, Parkinson's disease, amyotrophic lateral sclerosis, prion diseases, hereditary ataxia, dentatorubral-pallidoluysian atrophy and Wilson's disease, as well as cancer and skin aging $(3,4)$. Glutamate is the fundamental excitatory neurotransmitter, which is activated via N-methyl-D-aspartate receptors. Several important physiological functions are co-regulated by glutamate, and excessive concentrations of glutamate lead to the pathological effects caused by ROS. In addition, glutamate-associated neurotoxicity is implicated in numerous neuronal disorders (5). Hydrogen peroxide $\left(\mathrm{H}_{2} \mathrm{O}_{2}\right)$ is the product of a non-radical two-electron reduction of oxygen, which has previously been implicated in redox signaling and oxidative stress (6). Heme consists of $\mathrm{Fe}^{2+}$ and protoporphyrin IX, and is a prosthetic group that is present in hemoglobin and myoglobin (7). Free heme can lead to oxidative damage; therefore, in order to degrade heme, cells 
produce the rate-limiting enzyme heme oxygenase (HO). HO-1, which is an inducible form of $\mathrm{HO}$, degrades heme into three byproducts: Biliverdin, carbon monoxide (CO) and $\mathrm{Fe}^{2+}$. $\mathrm{CO}$ is generally considered to be toxic; however, recent studies have suggested that it exerts antiproliferative, anti-inflammatory and anti-apoptotic effects (8-10). Biliverdin is converted into bilirubin by biliverdin reductase, and numerous reports have suggested that bilirubin exerts antioxidant effects $(11,12) . \mathrm{Fe}^{2+}$ is immediately converted to ferritin, which has a protective effect against heme synthesis (13). Nuclear factor erythroid-derived 2-related factor-2 (Nrf2) has been reported to act as a positive regulator of detoxification enzyme gene expression, and recent studies have demonstrated that Nrf2 translocation regulates the expression of hundreds of cytoprotective genes, which counteract endogenously- or exogenously-generated oxidative stress (14). Nrf2 is a major upstream donor that induces HO expression (15). Mitogen-activated protein kinases (MAPKs) are associated with the majority of signal transduction pathways, including those involved in cell differentiation, cell proliferation, cell survival and cell transformation (16). The MAPK family comprises extracellular signal-regulated kinase (ERK), c-Jun NH2-terminal kinase (JNK) and p38 MAPK. Previous studies have demonstrated that MAPK is activated by oxidative stress or other stimuli, and that phosphorylation of MAPK regulates the expression of diverse genes and proteins, including HO-1 (17,18).

$\mathrm{KCHO}-1$ is a novel mixture comprised of $30 \%$ ethanol $(\mathrm{EtOH})$ extracts obtained from nine natural products: Curcuma longa, Salvia miltiorrhiza, Gastrodia elata, Chaenomeles sinensis, Polygala tenuifolia, Paeonia japonica, Glycyrrhiza uralensis, Atractylodes japonica and processed Aconitum carmichaeli. These natural products are well known as traditional medicinal herbs, which are used as alternative therapies in Korea and China, and recent studies have reported the beneficial effects of these herbs (19-25). In our previous study, it was suggested that $\mathrm{KCHO}-1$ exerted anti-inflammatory effects in BV2 microglia (26). Using an in vitro oxidative stress model, the present study aimed to explore the direct neuroprotective effects of $\mathrm{KCHO}-1$, and to determine the possible underlying mechanisms.

\section{Materials and methods}

Reagents. Dulbecco's modified Eagle's medium (DMEM) and other tissue culture reagents were purchased from Gibco (Thermo Fisher Scientific, Inc., Waltham, MA, USA). The HO activity inhibitor tin protoporphyrin IX (SnPP IX) was obtained from Porphyrin Products (Frontier Scientific, Logan, UT, USA). Primary antibodies, including rabbit polyclonal anti-HO-1 (1:1,000 dilution; cat. no. sc-10789), rabbit polyclonal anti-Nrf2 (1:1,000 dilution; cat. no. sc-722), goat polyclonal anti-lamin B (1:1,000 dilution; cat. no. sc-6216) and goat polyclonal anti-actin (1:1,000 dilution; cat. no. sc-1616) were purchased from Santa Cruz Biotechnology, Inc. (Heidelberg, Germany). Rabbit polyclonal anti-phosphorylated-ERK (1:1,000 dilution; cat. no. 9101) and rabbit polyclonal anti-ERK (1:1,000 dilution; cat. no. 9102) antibodies were obtained from Cell Signaling Technology, Inc. (Danvers, MA, USA). Secondary horseradish peroxidase (HRP)-conjugated polyclonal goat anti-rabbit IgG (1:1,000 dilution; cat. no. sc-2004) and HRP-conjugated normal goat IgG (1:1,000 dilution; cat. no. sc-2741) were purchased from Santa Cruz Biotechnology, Inc. The HO-1 inducer cobalt protoporphyrin IX (CoPP) and all other chemicals used were obtained from Sigma-Aldrich (St. Louis, MO, USA).

Extract preparation. C. longa, C. sinensis, P. tenuifolia, $P$. japonica, G. uralensis and A. japonica were purchased from Won Kwang Herb Co., Ltd. (Jinan, South Korea) in August 2013. S. miltiorrhiza and G. elata were purchased from Dongkyung Pharm. Co., Ltd. (Boeun, South Korea). Processed A. carmichaeli was purchased from Hanpoong Pharm \& Foods Co., Ltd. (Jeonju, South Korea). All voucher specimens were deposited at Hanpoong Pharm \& Foods Co., Ltd. [C. longa (HP2013-10-01), S. miltiorrhiza (HP2013-10-02), G. elata (HP2013-10-03), C. sinensis (HP2013-10-04), P. tenuifolia (HP2013-10-05), P. japonica (HP2013-10-06), G. uralensis (HP2013-10-07), A. japonica (HP2013-10-08), and processed A. carmichaeli (HP2013-10-09)]. To prepare the extract, C. longa (4 kg), S.miltiorrhiza (4 kg), G. elata (4 kg), C. sinensis $(2 \mathrm{~kg})$, P. tenuifolia $(2 \mathrm{~kg})$, P. japonica $(2 \mathrm{~kg})$, G. uralensis $(2 \mathrm{~kg})$, A. japonica $(2 \mathrm{~kg})$ and processed A. carmichaeli $(1 \mathrm{~kg})$ were mixed, pulverized and extracted in $30 \% \mathrm{EtOH}$ for $3 \mathrm{~h}$ at $84-90^{\circ} \mathrm{C}$. Subsequently, the mixture was concentrated using a rotary evaporator and lyophilized.

High-performance liquid chromatography (HPLC) analysis. The sample was analyzed by reversed-phase HPLC using a Sykam HPLC (Sykam GmbH, Eresing, Germany), equipped with S7131 Reagent Organizer, S2100 Solvent Delivery system, S7511 Vacuum Degaser, S5200 Sample Injection and S3210 UV/Vis Detector. HPLC-grade acetonitrile was purchased from Burdick \& Jackson ${ }^{\circledR}$ (Honeywell; Muskegon, MI, USA). Data processing was carried out using ChromStar DAD (GPC) software (Sykam GmbH). An Inertsil-ODS3 column (150x4.6 mm; particle size, $5 \mu \mathrm{m}$; GL Sciences Inc., Torrance, CA, USA) was used in the stationary phase. The mobile phase consisted of eluent A ( $0.1 \%$ formic acid in water with $10 \%$ acetonitrile) and eluent B (acetonitrile). The starting eluent was $100 \%$ A. The proportion of eluent B was increased linearly to $36 \%$ from 0 to $60 \mathrm{~min}$, increased to $60 \%$ from 60 to $90 \mathrm{~min}$, and increased to $100 \%$ from 90 to $110 \mathrm{~min}$. The detector wavelength was set over a range of 190-700 nm and recorded at $254 \mathrm{~nm}$. The flow rate was $1.0 \mathrm{ml} / \mathrm{min}$, and the injection volume was $20 \mu \mathrm{l}$. Identification was based on comparison of retention time and ultraviolet (UV) spectra with commercial standards. For each compound, peak areas were determined as the wavelength providing maximal UV absorbance.

Cell culture and viability assay. The HT22 mouse hippocampal cells were provided by Dr. Inhee-Mook (Seoul National University, Seoul, South Korea). The cells were maintained in DMEM supplemented with $10 \%$ heat-inactivated fetal bovine serum, penicillin $\mathrm{G}(100$ units $/ \mathrm{ml})$, streptomycin $(100 \mathrm{mg} / \mathrm{ml})$ and L-glutamine $(2 \mathrm{mM})$, and were incubated at $37^{\circ} \mathrm{C}$ in a humidified atmosphere containing $5 \% \mathrm{CO}_{2}$ and $95 \%$ air. For determination of cell viability, HT22 cells $\left(1 \times 10^{5}\right.$ cells/well in 24-well plates) were incubated with glutamate $(0.5-20 \mathrm{mM}$; Sigma-Aldrich) and $\mathrm{H}_{2} \mathrm{O}_{2}(10-500 \mu \mathrm{M})$ for $12 \mathrm{~h}$, or pre-treated with KCHO-1 (10-200 $\mu \mathrm{g} / \mathrm{ml}$; Sigma-Aldrich) for $12 \mathrm{~h}$. SnPPIX 
(50 $\mu \mathrm{M}$; Sigma-Aldrich) was used as an inhibitor of $\mathrm{HO}$, and trolox $(50 \mu \mathrm{M})$ was used as a positive control, incubated with 3-(4,5-dimethylthiazol-2-yl)-2,5-diphenyltetrazolium bromide (MTT; Sigma-Aldrich) at a final concentration of $0.5 \mathrm{mg} / \mathrm{ml}$ for $4 \mathrm{~h}$. Subsequently, the formazan that had formed was dissolved in acidic 2-propanol. Optical density (OD) was measured at $590 \mathrm{~nm}$ using a microplate reader (model no. 680; Bio-Rad Laboratories, Inc., Hercules, CA, USA). The OD of formazan in the control (untreated) cells was considered to represent $100 \%$ viability.

ROS measurement. To measure ROS, HT22 cells $\left(2.5 \times 10^{4}\right.$ cells/well in 24 -well plates) were treated with $5 \mathrm{mM}$ glutamate $(5 \mathrm{mM})$ in the presence or absence of $\mathrm{KCHO}-1$ $(10-200 \mu \mathrm{g} / \mathrm{ml})$ or SnPP IX $(50 \mu \mathrm{M})$ for $8 \mathrm{~h}$. After washing with phosphate-buffered saline (PBS), the cells were stained with $10 \mu \mathrm{M}$ 2',7'-dichlorofluorescein diacetate in Hank's balanced salt solution for $30 \mathrm{~min}$ in the dark. The cells were then washed twice with PBS and extracted with $1 \%$ Triton X-100 in PBS for $10 \mathrm{~min}$ at $37^{\circ} \mathrm{C}$. Fluorescence was recorded at an excitation wavelength of $490 \mathrm{~nm}$ and an emission wavelength of $525 \mathrm{~nm}$ (Spectramax Gemini XS; Molecular Devices, Sunnyvale, CA, USA). Cells were immediately observed under a laser-scanning confocal microscope (TCS SP2; Leica Microsystems, Wetzlar, Germany). Dichlorofluorescein fluorescence was excited at $488 \mathrm{~nm}$ with an argon laser, and the resulting emission was filtered with a 515-nm long pass filter.

Western blot analysis. HT22 cells were treated with $\mathrm{KCHO}-1$ (10-200 $\mu \mathrm{g}$ ), harvested and pelleted by centrifugation at $200 \times \mathrm{g}$ for $3 \mathrm{~min}$. Subsequently, the cells were washed with PBS and lysed using radioimmunoprecipitation assay lysis buffer [25 mmol/1 Tris-HCl buffer, $\mathrm{pH} 7.6 ; 150 \mathrm{mmol} / \mathrm{l} \mathrm{NaCl}$; $1 \%$ NP-40; $1 \%$ sodium deoxycholate; $0.1 \%$ sodium dodecyl sulfate (SDS)]. Protein concentration was determined using Bradford Assay Reagent (Bio-Rad Laboratories, Inc.). An equal amount of protein $(30 \mu \mathrm{g})$ from each sample was separated by $12 \%$ SDS-polyacrylamide gel electrophoresis and was then electrophoretically transferred onto a Hybond-enhanced chemiluminescence (ECL) nitrocellulose membrane (Bio-Rad Laboratories, Inc.). The membrane was blocked with $5 \%$ skim milk and incubated with primary antibodies at $4^{\circ} \mathrm{C}$ overnight, then incubated with secondary antibodies at room temperature for $1 \mathrm{~h}$. The bands were then visualized using ECL (RPN2232; GE Healthcare Life Sciences, Chalfont, UK) and quantified by densitometry using Image J software (version 1.47; National Institutes of Health, Bethesda, MA, USA). In the figures, representative blots from three independent experiments are presented, and the data are presented as the mean \pm standard deviation of three independent experiments. Nuclear and cytoplasmic cell extracts were prepared using NE-PER Nuclear and Cytoplasmic Extraction Reagents (Pierce Biotechnology, Inc., Rockford, IL USA).

Reverse transcription-quantitative polymerase chain reaction $(P C R)$ analysis. Total RNA was isolated from the cells using TRIzol ${ }^{\circledR}$ (Invitrogen; Thermo Fisher Scientific, Inc.), according to the manufacturer's protocol, and was quantified spectrophotometrically at $260 \mathrm{~nm}$ (ND-1000; Thermo Fisher Scientific, Inc.). Total RNA $(1 \mu \mathrm{g})$ was reverse transcribed using the High Capacity RNA-to-cDNA kit (Applied Biosystems; Thermo Fisher Scientific, Inc.) according to the manufacturer's protocol. cDNA was amplified using the SYBR Premix Ex Taq kit (Takara Bio. Inc., Shiga, Japan) on a StepOnePlus Real-Time PCR system (Applied Biosystems; Thermo Fisher Scientific, Inc.). Briefly, each reaction volume contained $10 \mu \mathrm{l}$ SYBR Green PCR Master Mix, $0.8 \mu \mathrm{M}$ each primer and diethyl pyrocarbonate-treated water, with a final reaction volume of $20 \mu \mathrm{l}$. The primer sequences were designed using PrimerQuest (Integrated DNA Technologies, Coralville, IA, USA). The primer sequences were as follows: HO-1, forward 5'-CTCTTGGCTGGCTTCCTT-3', reverse 5'-GGCTCCTTCCTCCTTTCC-3'; and glyceraldehyde 3-phosphate dehydrogenase (GAPDH), forward 5'-ACT TTGGTATCGTGGAAGGACT-3' and reverse 5'-GTA GAGGCAGGGATGATGTTCT-3. The optimal conditions for PCR amplification were established according to the manufacturer's protocol. The thermal cycling conditions used were as follows: Pre-denaturation at $95^{\circ} \mathrm{C}$ for $10 \mathrm{~min}$; denaturation at $95^{\circ} \mathrm{C}$ for $15 \mathrm{sec}$; and annealing at $60^{\circ} \mathrm{C}$ for $1 \mathrm{~min}$. A total of 40 cycles were performed. The data were analyzed using StepOne software (version 2.3; Applied Biosystems; Thermo Fisher Scientific, Inc.), and the cycle number at the linear amplification threshold (quantification cycle; $\mathrm{Cq}$ ) was recorded for the endogenous control gene and the target gene. Relative gene expression (target gene expression normalized to the expression of the endogenous control gene) was calculated using the comparative $\mathrm{Cq}$ method $\left(2^{-\Delta \Delta \mathrm{Cq}}\right)(27)$.

Statistical analysis. The data are presented as the mean \pm standard deviation of at least three independent experiments. To compare three or more groups, one-way analysis of variance followed by the Newman-Keuls post-hoc test was conducted. Statistical analysis was performed using GraphPad Prism software, version 3.03 (GraphPad Software, Inc., San Diego, CA, USA). $\mathrm{P}<0.05$ was considered to indicate a statistically significant difference.

\section{Results}

Effects of $\mathrm{KCHO}-1$, glutamate and $\mathrm{H}_{2} \mathrm{O}_{2}$ on $\mathrm{HT} 22$ cell viability. The present study examined $\mathrm{KCHO}-1$ cytotoxicity on HT22 cells using the MTT method. As shown in Fig. 1A, HT22 cells were incubated with $10-400 \mu \mathrm{g} / \mathrm{ml} \mathrm{KCHO}-1$, and cell viability was unchanged following treatment with all doses of KCHO-1. Therefore, in the present study, KCHO-1 was used at a concentration of $10-200 \mu \mathrm{g} / \mathrm{ml}$. Subsequently, the effects of glutamate $(0.5-20 \mathrm{mM})$ and $\mathrm{H}_{2} \mathrm{O}_{2}(10-500 \mu \mathrm{M})$ were determined on the viability of HT22 cells. Glutamate significantly reduced cell viability when used at a concentration of $>2 \mathrm{mM}$ (Fig. 1B). $\mathrm{H}_{2} \mathrm{O}_{2}$ induced cell death when used at a concentration of $>50 \mu \mathrm{M}$ (Fig. 1C). Therefore, glutamate and $\mathrm{H}_{2} \mathrm{O}_{2}$ were subsequently used at concentrations of $5 \mathrm{mM}$ and $100 \mu \mathrm{M}$, respectively.

Effects of $\mathrm{KCHO}-1$ on glutamate-induced oxidative neurotoxicity and ROS generation in HT22 cells. The present study investigated whether $\mathrm{KCHO}-1$ affected glutamate-induced oxidative cell toxicity and ROS generation in HT22 cells. Cell 

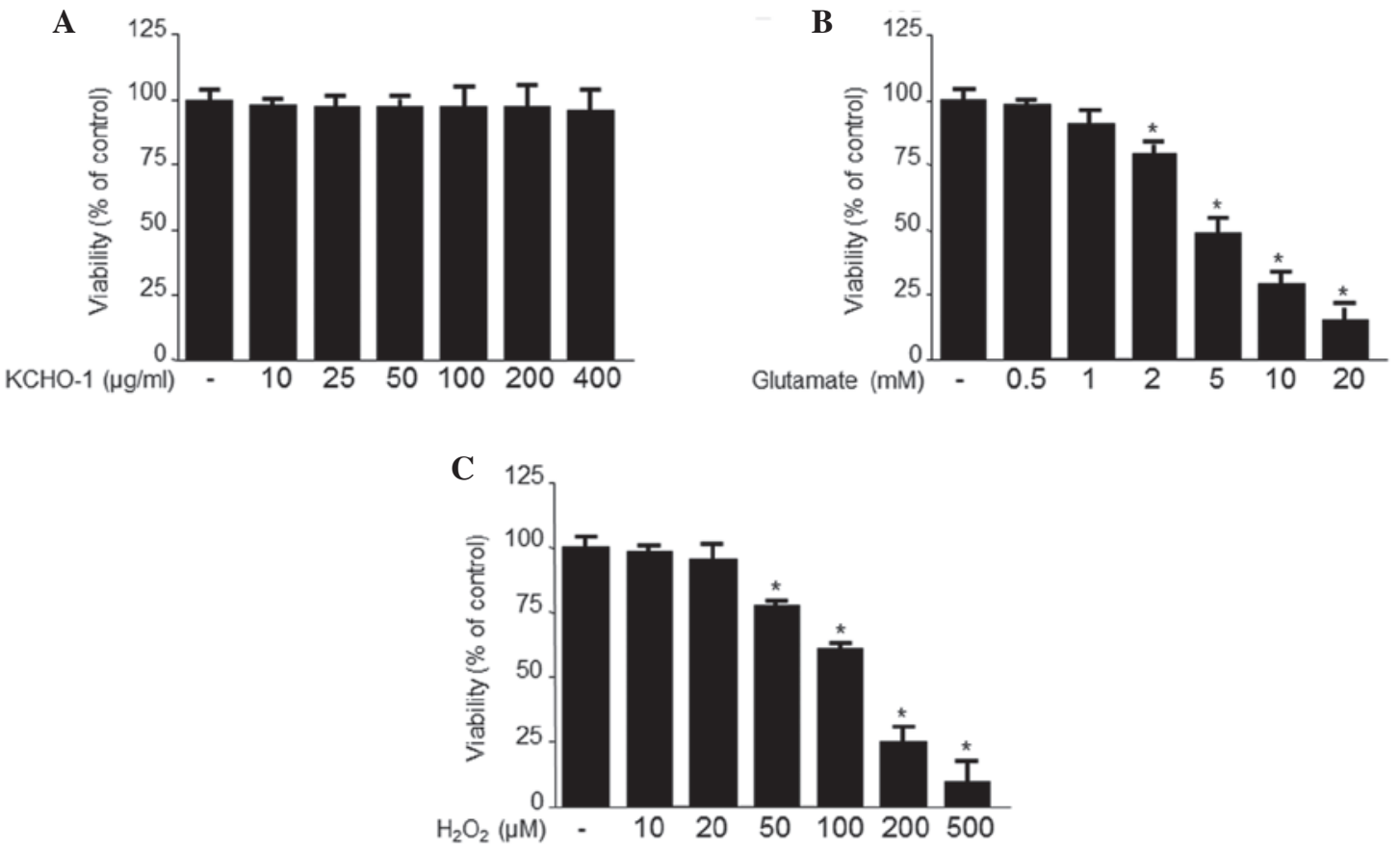

Figure 1. Effects of (A) KCHO-1, (B) glutamate and (C) hydrogen peroxide $\left(\mathrm{H}_{2} \mathrm{O}_{2}\right)$ on the viability of HT22 cells. HT22 cells were incubated for $48 \mathrm{~h}$ with various concentrations of KCHO-1 (10-400 $\mu \mathrm{g} / \mathrm{ml})$, glutamate $(0.5-20 \mathrm{mM})$ or $\mathrm{H}_{2} \mathrm{O}_{2}(10-500 \mu \mathrm{M})$. Data are presented as the mean \pm standard deviation of three independent experiments. ${ }^{*} \mathrm{P}<0.05$ vs. the control untreated cells.
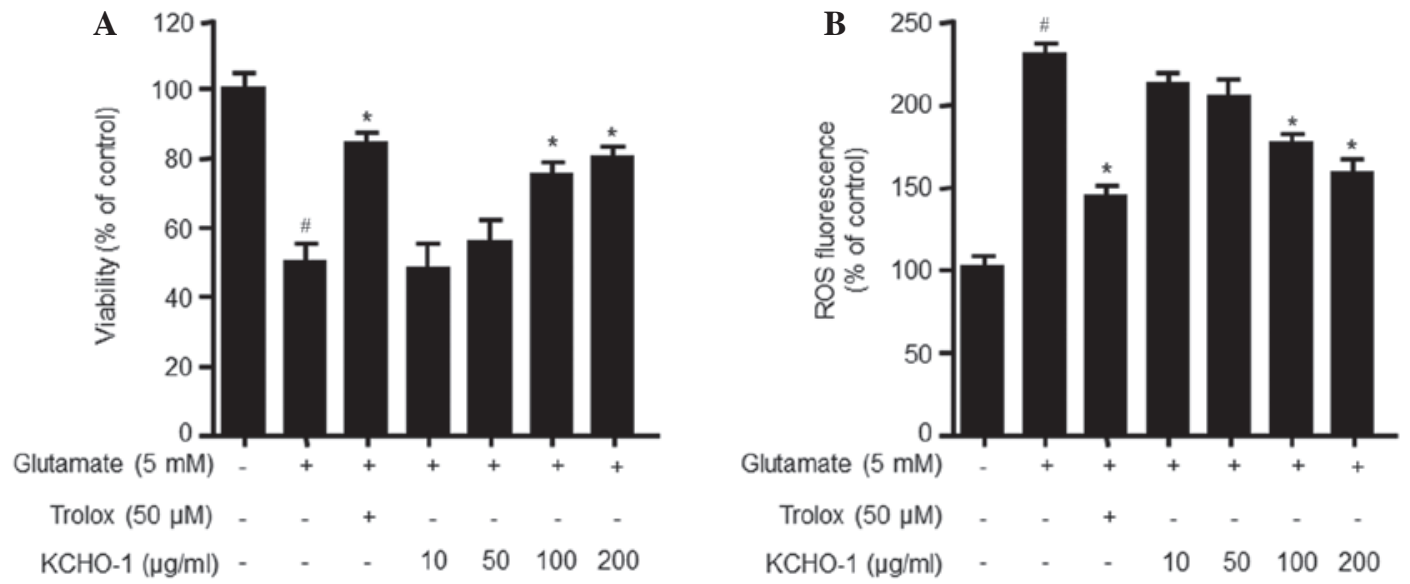

Figure 2. Effects of KCHO-1 on glutamate-induced (A) oxidative neurotoxicity and (B) reactive oxygen species (ROS) generation in HT22 cells. HT22 cells were pretreated with $\mathrm{KCHO}-1$ for $12 \mathrm{~h}$ and were then incubated for $12 \mathrm{~h}$ with glutamate $(5 \mathrm{mM})$. Exposure of $\mathrm{HT} 22$ cells to glutamate increased ROS production. Data are presented as the mean \pm standard deviation of three independent experiments. Trolox $(50 \mu \mathrm{M})$ was used as a positive control. ${ }^{*} \mathrm{P}<0.05 \mathrm{vs}$. the control group. ${ }^{*} \mathrm{P}<0.05$ vs. glutamate-treated cells.

viability was lower in the glutamate-treated cells compared with in the control group, whereas pretreatment with KCHO-1 $(100-200 \mu \mathrm{g} / \mathrm{ml})$ increased viability in a dose-dependent manner (Fig. 2A). In addition, glutamate treatment doubled ROS production, whereas KCHO-1 markedly attenuated this increase (Fig. 2B). The known antioxidant trolox was used as a positive control.

Effects of $\mathrm{KCHO}-1$ on $\mathrm{H}_{2} \mathrm{O}_{2}$-induced oxidative neurotoxicity and ROS generation in HT22 cells. The present study also determined the protective action of KCHO-1 against $\mathrm{H}_{2} \mathrm{O}_{2}$-induced neurotoxicity in HT22 cells. Compared with the untreated cells, treatment with $\mathrm{H}_{2} \mathrm{O}_{2}$ caused cell death and induced ROS production; however, pretreatment with KCHO-1 (100-200 $\mu \mathrm{g} / \mathrm{ml})$ increased viability in a concentration-dependent manner (Fig. 3A). Furthermore, KCHO-1 significantly suppressed $\mathrm{H}_{2} \mathrm{O}_{2}$-induced ROS generation (Fig. 3B).

Effects of KCHO-1 on the MRNA and protein expression levels of HO-1 in HT22 cells. The present study detected HO-1 expression in KCHO-1-treated HT22 cells. The HT22 cells were treated with non-cytotoxic concentrations of KCHO-1 (10-200 $\mu \mathrm{g} / \mathrm{ml})$ for $12 \mathrm{~h}$, and HO-1 mRNA (Fig. 4A) and protein expression levels (Fig. 4B) were increased in a dose-dependent manner. As a HO-1 inducer, CoPP was used 

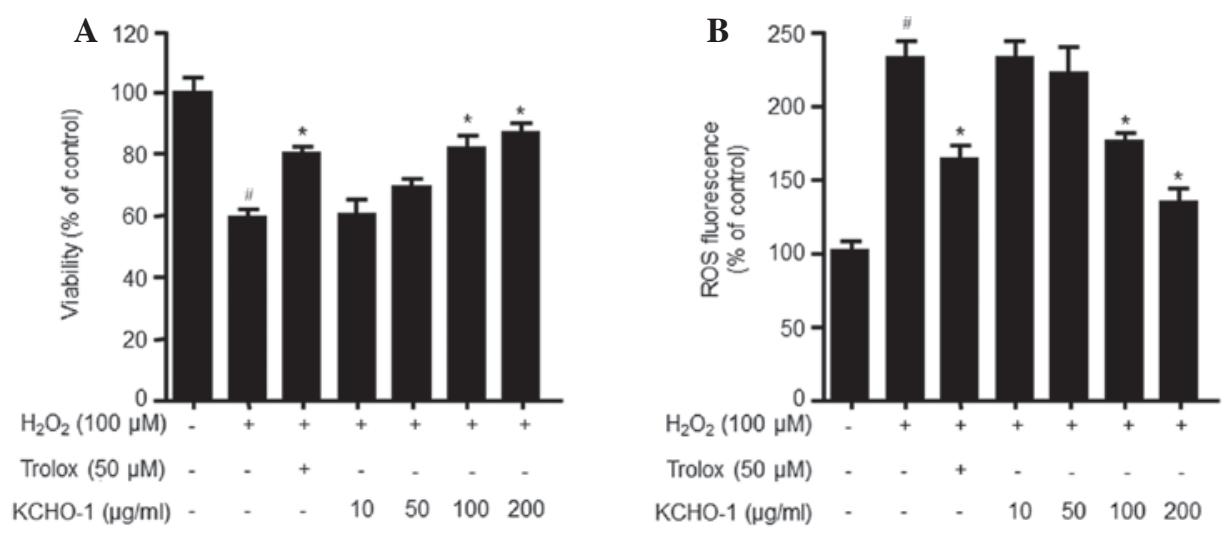

Figure 3. Effects of KCHO-1 on hydrogen peroxide $\left(\mathrm{H}_{2} \mathrm{O}_{2}\right.$ )-induced (A) oxidative neurotoxicity and (B) reactive oxygen species (ROS) generation in HT22 cells. HT22 cells were pretreated with KCHO-1 for $12 \mathrm{~h}$ and were then incubated for $12 \mathrm{~h}$ with $\mathrm{H}_{2} \mathrm{O}_{2}(100 \mu \mathrm{M})$. Exposure of HT22 cells to $\mathrm{H}_{2} \mathrm{O}_{2}$ increased ROS production. Data are presented as the mean \pm standard deviation of three independent experiments. Trolox $(50 \mu \mathrm{M})$ was used as a positive control. ${ }^{~} \mathrm{P}<0.05$ vs. the control group. " $\mathrm{P}<0.05$ vs. $\mathrm{H}_{2} \mathrm{O}_{2}$-treated cells.

A

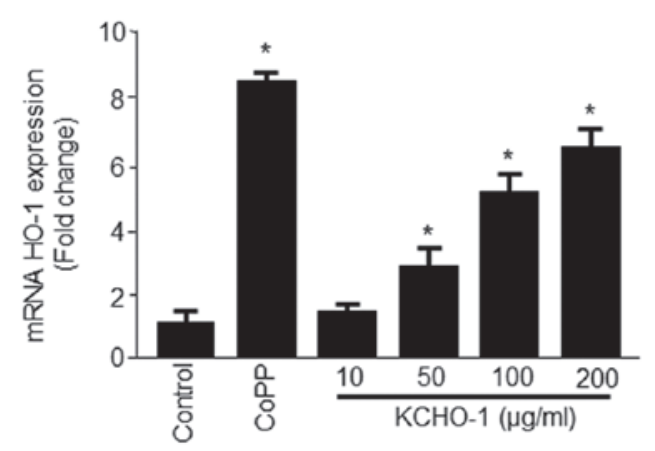

B
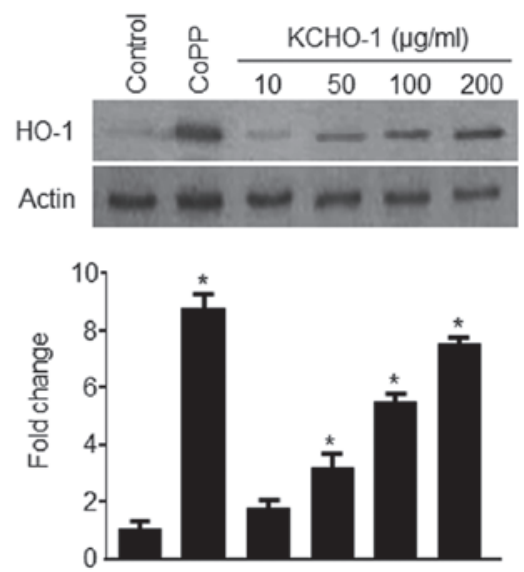

Figure 4. Effects of KCHO-1 on heme oxygenase (HO)-1 (A) mRNA and (B) protein expression in HT22 cells. HT22 cells were incubated with the indicated concentrations of KCHO-1 for $12 \mathrm{~h}(10-200 \mu \mathrm{g} / \mathrm{ml})$. Data are presented as the mean \pm standard deviation of three independent experiments. Cobalt protoporphyrin IX (CoPP; $20 \mu \mathrm{M})$ was used as a positive control. "P $<0.05$ vs. the control untreated cells.

as a positive control and dose-dependently increased $\mathrm{HO}-1$ mRNA and protein expression levels (Fig. 4A and B).

Effects of KCHO-1 on Nrf2 nuclear translocation in HT22 cells. Nrf2 nuclear translocation is a key inducer of HO-1 expression; therefore, the present study investigated whether pretreatment of HT22 cells with KCHO-1 also upregulated Nrf2 nuclear translocation (Fig. 5A and B). Cells were treated with KCHO-1 for $0.5,1.0$ or $1.5 \mathrm{~h}$ at a concentration of $200 \mu \mathrm{g} / \mathrm{ml}$. Nrf2 levels gradually decreased in the cytoplasm of HT22 cells (Fig. 5A), whereas nuclear Nrf2 levels markedly increased in a time-dependent manner (Fig. 5B).

Effects of $\mathrm{KCHO}-1$-induced $\mathrm{HO}-1$ expression via $\mathrm{Nrf} 2$ nuclear translocation on glutamate- and $\mathrm{H}_{2} \mathrm{O}_{2}$-induced oxidative neurotoxicity. The present study subsequently assessed whether $\mathrm{KCHO}-1$-induced $\mathrm{HO}-1$ upregulation was responsible for the observed cytoprotective effects. HT22 cells were co-treated with $200 \mu \mathrm{g} / \mathrm{ml} \mathrm{KCHO}-1$ for $12 \mathrm{~h}$ in the absence or presence of the HO inhibitor SnPP IX. SnPP partially inhibited the ability of KCHO-1 to suppress glutamate-induced cytotoxicity and ROS generation (Fig. 6A and B). Furthermore, SnPP partially inhibited the ability of KCHO-1 to suppress $\mathrm{H}_{2} \mathrm{O}_{2}$-induced cytotoxicity and $\mathrm{ROS}$ generation (Fig. 6C and D). These results suggest that $\mathrm{HO}-1$ expression may be required for the inhibition of $\mathrm{H}_{2} \mathrm{O}_{2}$-induced ROS generation.

Effects of KCHO-1-induced ERK activation on HO-1 expression, and glutamate- and $\mathrm{H}_{2} \mathrm{O}_{2}$-induced neurotoxicity. To investigate the role of MAPKs in KCHO-1-induced HO-1 expression, the present study examined the effects of specific inhibitors, including PD98059 (ERK inhibitor), SP600125 (JNK inhibitor) and SB203580 (p38 inhibitor). As shown in Fig. 7A, ERK inhibition suppressed KCHO-1-induced HO-1 expression, whereas JNK and p38 inhibition did not. In addition, ERK phosphorylation was detected following KCHO-1 treatment between 15 and 60 min (Fig. 7B). PD98059 also partially reversed the ability of $\mathrm{KCHO}-1$ to inhibit glutamate- and $\mathrm{H}_{2} \mathrm{O}_{2}$-induced cell toxicity (Fig. 7C and D). Data from the HPLC analysis of KCHO-1 was obtained in the form of chromatograms by monitoring responses at $254 \mathrm{~nm}$. As presented in Fig. 8, the retention time of the main peak was $38.858 \mathrm{~min}$. 

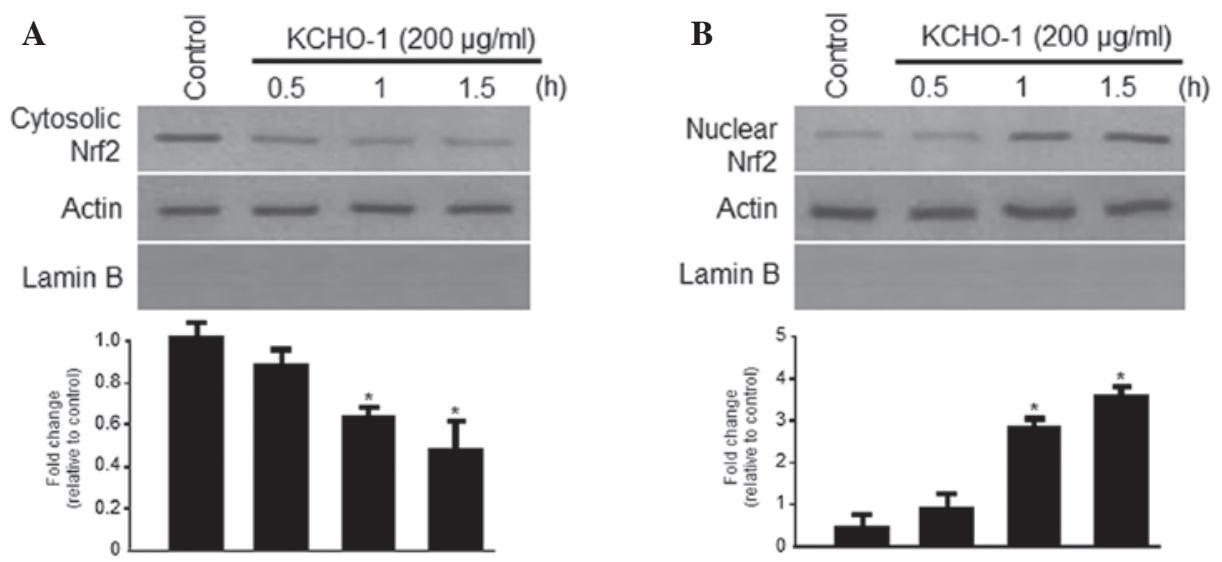

Figure 5. Effects of KCHO-1 on the nuclear translocation of nuclear factor erythroid-derived 2-related factor-2 (Nrf2) in HT22 cells. HT22 cells were treated with KCHO-1 $(200 \mu \mathrm{g} / \mathrm{ml})$ for $0.5,1$ or $1.5 \mathrm{~h}$. The nuclei were fractionated from the cytosol using PER-Mammalian Protein Extraction buffer. Nrf2 (A) cytoplasmic and (B) nuclear protein expression was detected using western blot analysis, and representative blots of three independent experiments are shown. Data are presented as the mean \pm standard deviation of three independent experiments. $\mathrm{P}<0.05$ vs. the control untreated cells.

A
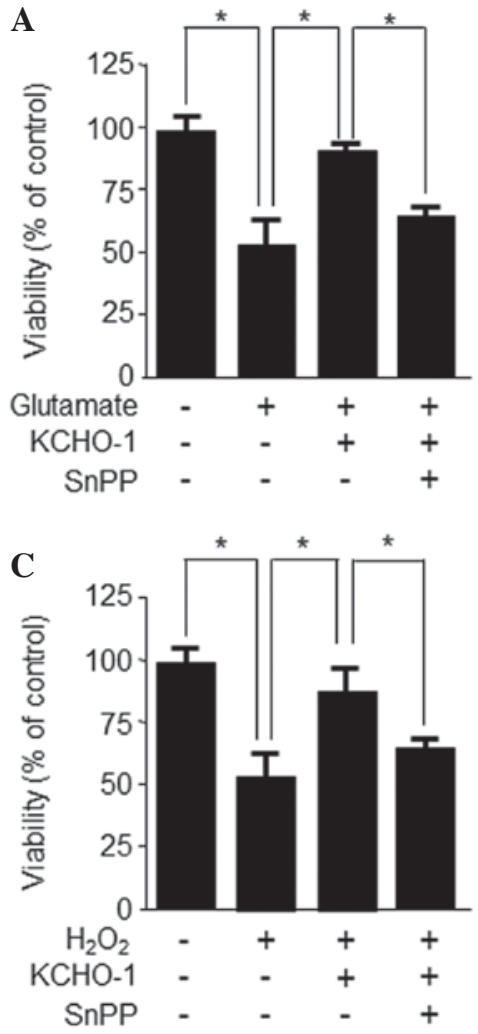
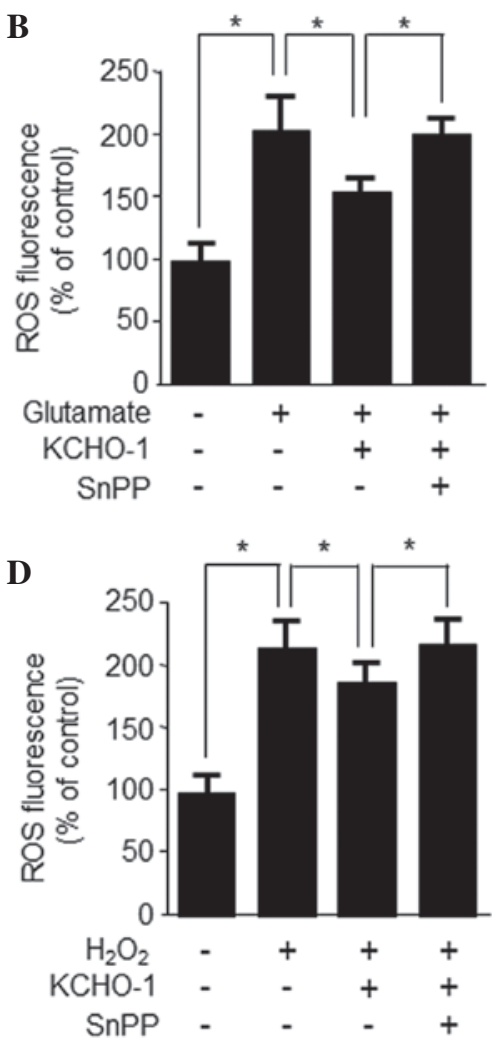

Figure 6. Effects of $\mathrm{KCHO}-1$-induced nuclear factor erythroid-derived 2-related factor-2-mediated heme oxygenase-1 expression on glutamate- and hydrogen peroxide $\left(\mathrm{H}_{2} \mathrm{O}_{2}\right)$-induced oxidative neurotoxicity and reactive oxygen species (ROS) generation in HT22 cells. HT22 cells were treated with $200 \mu \mathrm{g} / \mathrm{ml}$ KCHO-1 in the presence or absence of $50 \mu \mathrm{M}$ tin protoporphyrin IX (SnPP). (A) Cell viability and (B) ROS generation were measured following treatment with glutamate (5 mM) for $12 \mathrm{~h}$. (C) Cell viability and (D) ROS generation were also measured following treatment with $\mathrm{H}_{2} \mathrm{O}_{2}(100 \mu \mathrm{M})$ for $12 \mathrm{~h}$. Data are presented as the mean \pm standard deviation of three independent experiments. ${ }^{*} \mathrm{P}<0.05$.

\section{Discussion}

Oxidative stress in brain tissue may occur physiologically, as a result of neurodegenerative disorders (28). Therefore, the authors of the present study have focused on the mechanism of action of natural products against neurodegenerative diseases via HO-1 regulation (29-32). In our previous study, the extract KCHO-1 was developed (26). The present study investigated the association of HO-1 with the neuroprotective action of KCHO-1, via Nrf2 nuclear translocation. To determine the therapeutic potential of $\mathrm{KCHO}-1$, its direct neuroprotective effects on glutamate- and $\mathrm{H}_{2} \mathrm{O}_{2}$-induced oxidative damage were investigated in HT22 mouse hippocampal cells.

The HT22 immortalized neuronal cell line has been used as an in vitro model for mechanistic identification of glutamate-induced oxidative damage. In the central nervous 
A

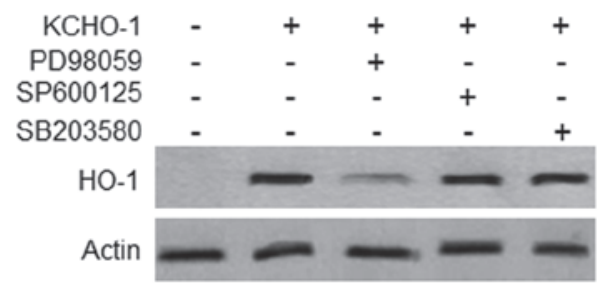

C

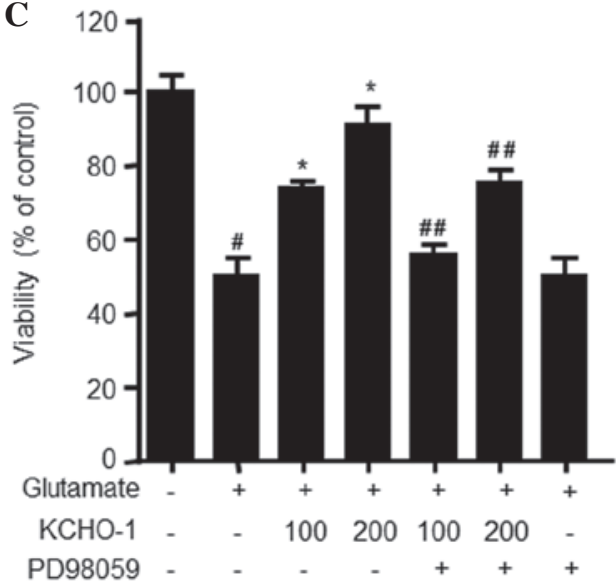

B

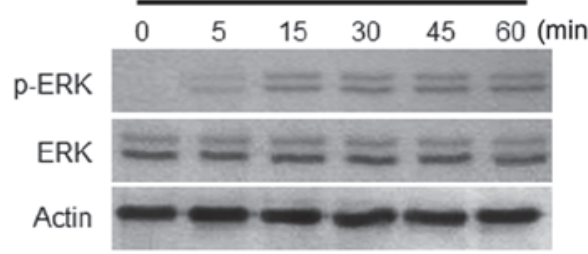

D

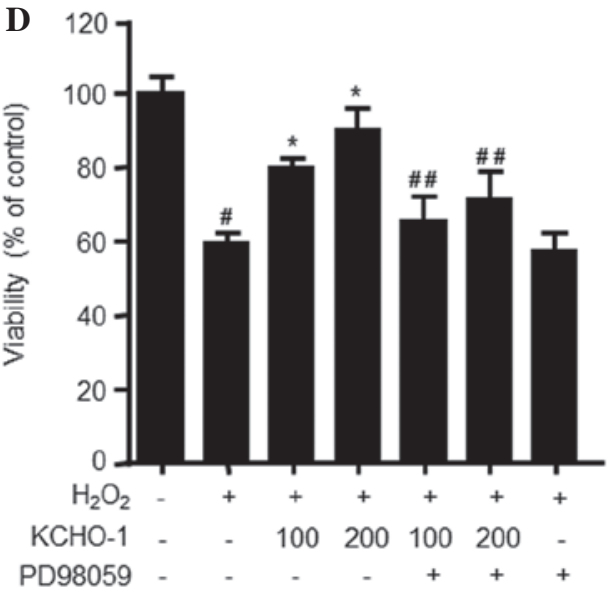

Figure 7. Effects of KCHO-1 induced extracellular signal-regulated kinase activation on heme oxygenase (HO)-1 expression, and glutamate- and hydrogen peroxide $\left(\mathrm{H}_{2} \mathrm{O}_{2}\right)$-induced neurotoxicity. (A) Cells were incubated with the indicated concentration of KCHO-1 $(200 \mu \mathrm{g} / \mathrm{ml})$ for $12 \mathrm{~h}$ in the presence or absence of PD98059 $(20 \mu \mathrm{M})$, SP600125 $(25 \mu \mathrm{M})$ or SB203580 $(20 \mu \mathrm{M})$, and western blotting was performed with a HO-1 antibody. (B) HT22 cells were treated with KCHO-1 (200 $\mu \mathrm{g} / \mathrm{ml})$ for the indicated times. HT22 cells untreated or treated with KCHO-1 (100 or $200 \mu \mathrm{g} / \mathrm{ml})$ in the presence or absence of PD98059 $(20 \mu \mathrm{M})$ for $12 \mathrm{~h}$ were exposed to (C) $5 \mathrm{mM}$ glutamate or (D) $100 \mu \mathrm{M} \mathrm{H}_{2} \mathrm{O}_{2}$ for $12 \mathrm{~h}$. Data are presented as the mean \pm standard deviation of three independent experiments. ${ }^{~} \mathrm{P}<0.05$ vs. glutamate $(5 \mathrm{mM})$ - or $\mathrm{H}_{2} \mathrm{O}_{2}(100 \mu \mathrm{M})$-treated cells; ${ }^{\# \#} \mathrm{P}<0.05$ vs. KCHO-1-treated cells; ${ }^{~} \mathrm{P}<0.05$ vs. the control group.

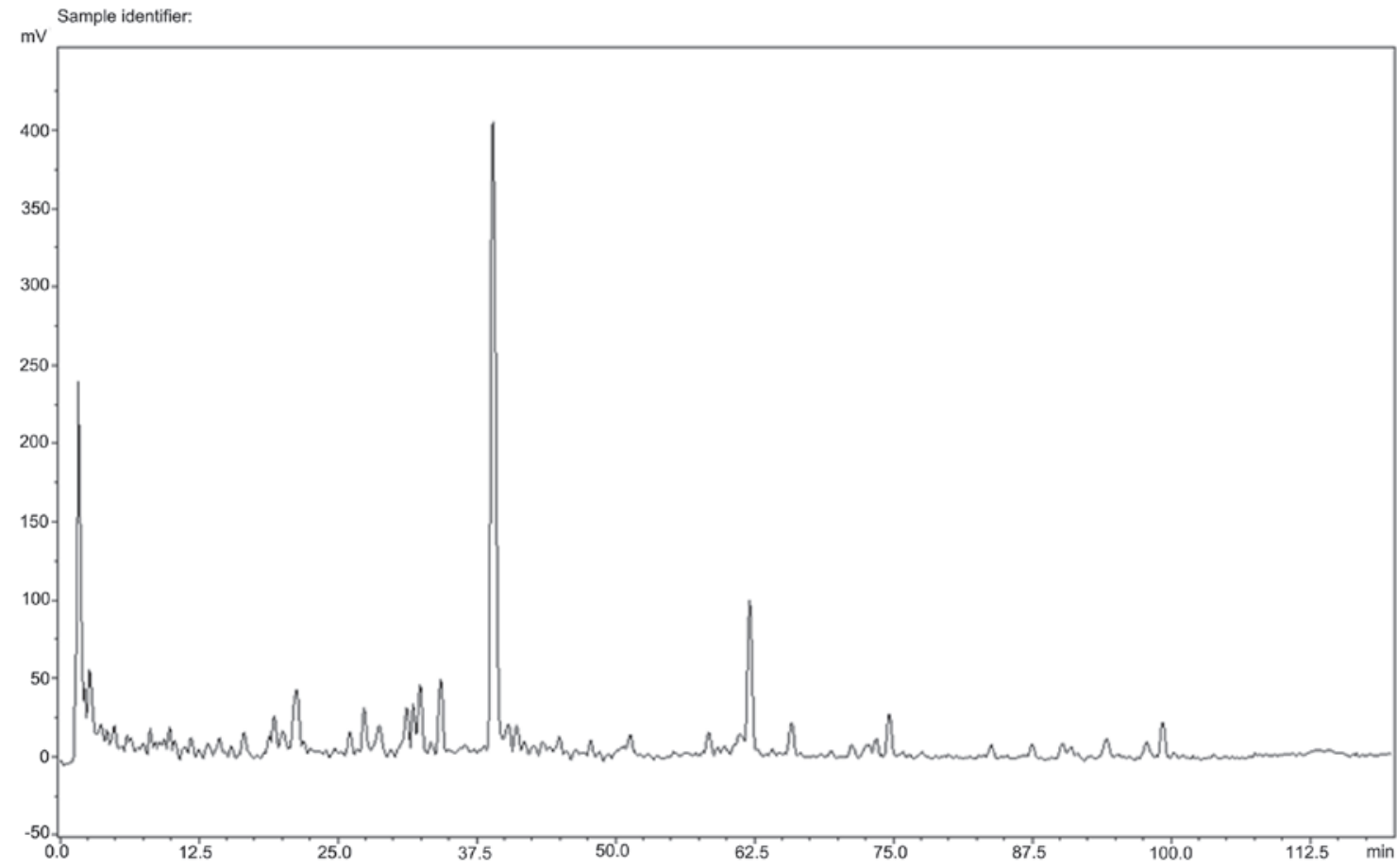

Figure 8. High-performance liquid chromatography (HPLC) chromatograms of KCHO-1. Chromatograms were obtained via HPLC using KCHO-1 dissolved in acetonitrile at a concentration of $10 \mathrm{mg} / \mathrm{ml}$. The method utilized a hydro column at a flow rate of $1 \mathrm{ml} / \mathrm{min}$, with an acetonitrile/water/formic acid gradient for $110 \mathrm{~min}$, and the wavelength was detected at $254 \mathrm{~nm}$. The ultraviolet spectra peak at $38.858 \mathrm{~min}$ was identified as the major component of KCHO-1.

system, glutamate is the main excitatory neurotransmitter that is released by nerve cells in the brain; however, glutamate toxicity induces neuronal cell death, which is associated with acute insults and chronic neurodegenerative disorders $(33,34)$. Glutamate-mediated oxidative stress is caused by inhibiting cellular cystine uptake, leading to glutathione depletion or 
ROS generation and elevated $\mathrm{Ca}^{2+}$ levels (35). $\mathrm{H}_{2} \mathrm{O}_{2}$ is the product of a non-radical two-electron reduction of oxygen, and has been reported to have a key role in oxidative cell death (6). Therefore, it may be therapeutically beneficial to reduce the damaging effects of oxidative glutamate or $\mathrm{H}_{2} \mathrm{O}_{2}$ toxicity. As shown in Fig. 1, the present study initially evaluated the action of glutamate $(5 \mathrm{mM})$ and $\mathrm{H}_{2} \mathrm{O}_{2}(100 \mu \mathrm{M})$ on the viability of HT22 cells. Subsequently, it was investigated whether KCHO-1 was able to affect glutamate- or $\mathrm{H}_{2} \mathrm{O}_{2}$-induced oxidative neurotoxicity and ROS generation in HT22 cells. KCHO-1 significantly suppressed glutamate- and $\mathrm{H}_{2} \mathrm{O}_{2}$-induced cell damage and ROS generation (Figs. 2 and 3).

In our previous studies, it was demonstrated that HO-1 expression may have an important role in the protection of HT22 cells $(36,37)$. It has been suggested that the role of $\mathrm{HO}-1$ in heme degradation may offer cells protection against oxidative insults and maintain cellular homeostasis. The antioxidant activities of HO-1 have been observed in Alzheimer's disease, sepsis, endotoxemia, surgical stress, ischemia reperfusion injury and psychological stress $(26,38)$. In the present study, cells were treated with non-cytotoxic concentrations of KCHO-1. The results indicated that the mRNA and protein expression levels of HO-1 were increased in HT22 cells (Fig. 4). Furthermore, the present study assessed whether $\mathrm{KCHO}-1$-mediated HO-1 upregulation was responsible for its protective effects on HT22 cells. Treatment with the HO-1 inhibitor SnPP partially reversed the ability of KCHO-1 to inhibit $\mathrm{H}_{2} \mathrm{O}_{2}$-induced cell death and ROS generation (Fig. 6). These results suggested that HO-1 expression may be required to inhibit $\mathrm{H}_{2} \mathrm{O}_{2}$-induced ROS generation. Nrf2 is a basic leucine zipper transcription factor, which resides in the cytoplasm bound to Keap-1. Following stimulation with inducers, Nrf2 translocates into the nucleus (39-41). Nrf2 has been reported to induce the expression of antioxidant proteins, including HO-1 (42). The present study revealed that $\mathrm{KCHO}-1$ significantly upregulated Nrf2 and efficiently promoted its translocation into the nucleus, thus suggesting that $\mathrm{KCHO}-1$-induced HO-1 expression may be associated with Nrf2 nuclear translocation (Fig. 5).

The present study also demonstrated that the ERK pathway is involved in $\mathrm{KCHO}-1$-induced HO-1 expression (Fig. 7). MAPK is one of the most common cellular response signaling pathways, which responds to various extracellular stimuli. There are three subfamilies of MAPK: p38 kinase, ERK1/2 and JNK (43). MAPKs are initiated in response to various extracellular stimuli, particularly oxidative stress. Previous studies have reported that activation of MAPK pathways may contribute to HO-1 gene expression $(44,45)$. In the present study, KCHO-1-induced HO-1 gene expression was shown to be associated with the ERK pathway, since treatment with the ERK inhibitor, PD98059, suppressed KCHO-1-induced HO-1 expression; however, JNK and p38 inhibition did not affect HO-1 expression. As expected, treatment with the ERK pathway inhibitor also abolished $\mathrm{KCHO}-1$-induced cytoprotection (Fig. 7). These results indicated that KCHO-1-induced HO-1 expression in HT22 cells may be mediated by the Nrf2 or ERK pathways.

In conclusion, the results of the present study suggested that KCHO-1 may effectively prevent glutamate- or $\mathrm{H}_{2} \mathrm{O}_{2}$-induced oxidative cell damage in a murine hippocampal cell line. KCHO-1-induced HO-1 upregulation via ERK and
Nrf2 pathways appears to have a central role in the protection of HT22 cells. These results may provide an insight into the mechanisms underlying $\mathrm{KCHO}-1$-induced neuronal cell protection and HO-1 enzyme induction. Therefore, $\mathrm{KCHO}-1$ may be considered a potential agent for the treatment of neurodegenerative diseases.

\section{Acknowledgements}

The present study was supported by the Traditional Korean Medicine R\&D Program funded by the Ministry of Health $\&$ Welfare through the Korea Health Industry Development Institute (KHIDI) (grant no. HI11C2142).

\section{References}

1. Chen YR and Zweier JL: Cardiac mitochondria and reactive oxygen species generation. Circ Res 114: 524-537, 2014.

2. Ray PD, Huang BW and Tsuji Y: Reactive oxygen species (ROS) homeostasis and redox regulation in cellular signaling. Cell Signal 24: 981-990, 2012.

3. Paulsen JS, Nance M, Kim JI, Carlozzi NE, Panegyres PK, Erwin C, Goh A, McCusker E and Williams JK: A review of quality of life after predictive testing for and earlier identification of neurodegenerative diseases. Prog Neurobiol 110: 2-28, 2013.

4. Sena LA and Chandel NS: Physiological roles of mitochondrial reactive oxygen species. Mol Cell 48: 158-167, 2012.

5. Dobrek L and Thor P: Glutamate NMDA receptors in pathophysiology and pharmacotherapy of selected nervous system diseases. Postepy Hig Med Dosw (Online) 65: 338-346, 2011.

6. Sies $\mathrm{H}$ : Role of metabolic $\mathrm{H}_{2} \mathrm{O}_{2}$ generation: Redox signaling and oxidative stress. J Biol Chem 289: 8735-8741, 2014.

7. Girvan HM and Munro AW: Heme sensor proteins. J Biol Chem 288: 13194-13203, 2013.

8. Wang X, Cao J, Sun BW, Liu DD, Liang F and Gao L: Exogenous carbon monoxide attenuates inflammatory responses in the small intestine of septic mice. World J Gastroenterol 18: 5719-5728, 2012.

9. Ryter SW and Choi AM: Heme oxygenase-1/carbon monoxide: From metabolism to molecular therapy. Am J Respir Cell Mol Biol 41: 251-260, 2009.

10. Al-Owais MM, Scragg JL, Dallas ML, Boycott HE, Warburton P, Chakrabarty A, Boyle JP and Peers C: Carbon monoxide mediates the anti-apoptotic effects of heme oxygenase-1 in medulloblastoma DAOY cells via $\mathrm{K}^{+}$channel inhibition. J Biol Chem 287: 24754-24764, 2012.

11. Parfenova H, Leffler CW, Basuroy S, Liu J and Fedinec AL: Antioxidant roles of heme oxygenase, carbon monoxide, and bilirubin in cerebral circulation during seizures. J Cereb Blood Flow Metab 32: 1024-1034, 2012.

12. Jansen T, Hortmann M, Oelze M, Opitz B, Steven S, Schell R, Knorr M, Karbach S, Schuhmacher S, Wenzel P, et al: Conversion of biliverdin to bilirubin by biliverdin reductase contributes to endothelial cell protection by heme oxygenase-1-evidence for direct and indirect antioxidant actions of bilirubin. J Mol Cell Cardiol 49: 186-195, 2010.

13. Lipiński P, Jarzabek Z, Broniek S and Zagulski T: Protective effect of tissue ferritins in experimental Escherichia coli infection of mice in vivo. Int J Exp Pathol 72: 623-630, 1991.

14. Chen B, Lu Y, Chen Y and Cheng J: The role of Nrf2 in oxidative stress-induced endothelial injuries. J Endocrinol 225: R83-R99, 2015.

15. Farombi EO and Surh YJ: Heme oxygenase-1 as a potential therapeutic target for hepatoprotection. J Biochem Mol Biol 39: 479-491, 2006.

16. Kim EK and Choi EJ: Pathological roles of MAPK signaling pathways in human diseases. Biochim Biophys Acta 1802: 396-405, 2010.

17. Wang LH, Li Y, Yang SN, Wang FY, Hou Y, Cui W, Chen K, Cao Q, Wang S, Zhang TY, et al: Gambogic acid synergistically potentiates cisplatin-induced apoptosis in non-small-cell lung cancer through suppressing NF- $\kappa \mathrm{B}$ and MAPK/HO-1 signalling. Br J Cancer 110: 341-352, 2014. 
18. Lee DS, Kim KS, Ko W, Li B, Jeong GS, Jang JH, Oh H and Kim YC: The cytoprotective effect of sulfuretin against tert-butyl hydroperoxide-induced hepatotoxicity through Nrf2/ARE and JNK/ERK MAPK-mediated heme oxygenase-1 expression. Int J Mol Sci 15: 8863-8877, 2014.

19. Ringman JM, Frautschy SA, Cole GM, Masterman DL and Cummings JL: A potential role of the curry spice curcumin in Alzheimer's disease. Curr Alzheimer Res 2: 131-136, 2005.

20. Huang GB, Zhao T, Muna SS, Jin HM, Park JI, Jo KS, Lee BH, Chae SW, Kim SY, Park SH, et al: Therapeutic potential of Gastrodia elata Blume for the treatment of Alzheimer's disease. Neural Regen Res 8: 1061-1070, 2013.

21. Li Z, Liu Y, Wang L, Liu X, Chang Q, Guo Z, Liao Y, Pan R and Fan TP: Memory-enhancing effects of the crude extract of Polygala tenuifolia on aged mice. Evid Based Complement Alternat Med 2014: 392324, 2014

22. Dittmann K, Gerhäuser Klimo $C K$ and Hamburger $M$ : HPLC-based activity profiling of Salvia miltiorrhiza for MAO A and iNOS inhibitory activities. Planta Med 70: 909-913, 2004.

23. Han YJ, Je JH, Kim SH, Ahn SM, Kim HN, Kim YR, Choi YW, Shin HK and Choi BT: Gastrodia elata shows neuroprotective effects via activation of PI3K signaling against oxidative glutamate toxicity in HT22 cells. Am J Chin Med 42: 1007-1019, 2014.

24. Hu Y, Liu M, Liu P, Guo DH, Wei RB and Rahman K: Possible mechanism of the antidepressant effect of 3,6'-disinapoyl sucrose from Polygala tenuifolia Willd. J Pharm Pharmacol 63: 869-874, 2011.

25. Hwang CK and Chun HS: Isoliquiritigenin isolated from licorice Glycyrrhiza uralensis prevents 6-hydroxydopamine-induced apoptosis in dopaminergic neurons. Biosci Biotechnol Biochem 76: 536-543, 2012.

26. Lee DS, Ko W, Yoon CS, Kim DC, Yun J, Lee JK, Jun KY, Son I, Kim DW, Song BK, et al: KCHO-1, a novel antineuroinflammatory agent, inhibits lipopolysaccharide-induced neuroinflammatory responses through Nrf2-mediated heme oxygenase-1 expression in mouse BV2 microglia cells. Evid Based Complement Alternat Med 2014: 357154, 2014.

27. Livak KJ and Schmittgen TD: Analysis of relative gene expression data using real-time quantitative PCR and the 2(-Delta Delta C(T)) Method. Methods 25: 402-408, 2001.

28. Shimomura H, Ogawa H, Takazoe K, Soejima H, Miyamoto S, Sakamoto T, Kawano H, Suefuji H, Nishikawa H, Arai H, et al: Comparison of urinary biopyrrin levels in acute myocardial infraction (after reperfusion therapy) versus stable angina pectoris and their usefulness in predicting subsequent cardiac events. Am J Cardiol 90: 108-111, 2002.

29. Hald A and Lotharius J: Oxidative stress and inflammation in Parkinson's disease: Is there a causal link? Exp Neurol 193 279-290, 2005

30. Lee DS, Ko W, Quang TH, Kim KS, Sohn JH, Jang JH, Ahn JS, Kim YC and Oh H: Penicillinolide A: A new anti-inflammatory metabolite from the marine fungus Penicillium sp. SF-5292. Mar Drugs 11: 4510-4526, 2013.

31. Lee DS, Kim KS, Ko W, Li B, Keo S, Jeong GS, Oh H and Kim YC: The neoflavonoid latifolin isolated from $\mathrm{MeOH}$ extract of Dalbergia odorifera attenuates inflammatory responses by inhibiting $\mathrm{NF}-\kappa \mathrm{B}$ activation via Nrf2-mediated heme oxygenase-1 expression. Phytother Res 28: 1216-1223, 2014.
32. Lee DS, Li B, Im NK, Kim YC and Jeong GS: 4,2',5'-trihydroxy-4'methoxychalcone from Dalbergia odorifera exhibits anti-inflammatory properties by inducing heme oxygenase- 1 in murine macrophages. Int Immunopharmacol 16: 114-121, 2013.

33. Keller JN and Mattson MP: Roles of lipid peroxidation in modulation of cellular signaling pathways, cell dysfunction and death in the nervous system. Rev Neurosci 9: 105-116, 1998.

34. Siesjö BK: Cell damage in the brain: A speculative synthesis. J Cereb Blood Flow Metab 1: 155-185, 1981.

35. Mattson MP: Apoptosis in neurodegenerative disorders. Nat Rev Mol Cell Biol 1: 120-129, 2000.

36. Lee DS and Jeong GS: Arylbenzofuran isolated from Dalbergia odorifera suppresses lipopolysaccharide-induced mouse BV2 microglial cell activation, which protects mouse hippocampal HT22 cells death from neuroinflammation-mediated toxicity. Eur J Pharmacol 728: $1-8,2014$

37. Lee DS, Ko W, Kim DC, Kim YC and Jeong GS: Cudarflavone B provides neuroprotection against glutamate-induced mouse hippocampal HT22 cell damage through the Nrf2 and PI3K/Akt signaling pathways. Molecules 19: 10818-10831, 2014.

38. Yamaguchi $T$, Hasizume $T$, Tanaka $M$, Nakayama $M$, Sugimoto A, Ikeda S, Nakajima $\mathrm{H}$ and Horio F: Bilirubin oxidation provoked by endotoxin treatment is suppressed by feeding ascorbic acid in a rat mutant unable to synthesize ascorbic acid. Eur J Biochem 245: 233-240, 1997.

39. Lee BS, Heo J, Kim YM, Shim SM, Pae HO, Kim YM and Chung HT: Carbon monoxide mediates heme oxygenase 1 induction via Nrf2 activation in hepatoma cells. Biochem Biophys Res Commun 343: 965-972, 2006.

40. Qiang W, Cahill JM, Liu J, Kuang X, Liu N, Scofield VL, Voorhees JR, Reid AJ, Yan M, Lynn WS and Wong PK: Activation of transcription factor Nrf-2 and its downstream targets in response to moloney murine leukemia virus ts1-induced thiol depletion and oxidative stress in astrocytes. J Virol 78: 11926-11938, 2004

41. Kim KM, Pae HO, Zheng M, Park R, Kim YM and Chung HT: Carbon monoxide induces heme oxygenase-1 via activation of protein kinase R-like endoplasmic reticulum kinase and inhibits endothelial cell apoptosis triggered by endoplasmic reticulum stress. Circ Res 101: 919-927, 2007.

42. Lim HJ, Lee KS, Lee S, Park JH, Choi HE, Go SH, Kwak HJ and Park HY: 15d-PGJ2 stimulates HO-1 expression through p38 MAP kinase and Nrf-2 pathway in rat vascular smooth muscle cells. Toxicol Appl Pharmacol 223: 20-27, 2007.

43. Choi BH, Hur EM, Lee JH, Jun DJ and Kim KT: Protein kinase Cdelta-mediated proteasomal degradation of MAP kinase phosphatase-1 contributes to glutamate-induced neuronal cell death. J Cell Sci 119: 1329-1340, 2006.

44. Satoh T, Nakatsuka D, Watanabe Y, Nagata I, Kikuchi H and Namura S: Neuroprotection by MAPK/ERK kinase inhibition with U0126 against oxidative stress in a mouse neuronal cell line and rat primary cultured cortical neurons. Neurosci Lett 288: 163-166, 2000.

45. Elbirt KK, Whitmarsh AJ, Davis RJ and Bonkovsky HL: Mechanism of sodium arsenite-mediated induction of heme oxygenase-1 in hepatoma cells. Role of mitogen-activated protein kinases. J Biol Chem 273: 8922-8931, 1998. 